\title{
Entrepreneurship and Service Learning of Students of Information Sciences and Informatics
}

\author{
Hana Josić \\ Faculty of Humanities and Social Sciences, University of Zagreb, Croatia \\ hjosic@ffzg.hr \\ Nives Mikelić Preradović \\ Faculty of Humanities and Social Sciences, University of Zagreb, Croatia \\ nmikelic@ffzg.hr
}

\begin{abstract}
Summary:
The first aim of this paper was to research the attitudes of students of information sciences and informatics towards acquiring entrepreneurial skills during their study. The second aim was to determine the level and frequency of students' civic (community) engagement. The sample included 211 (mostly) undergraduate students from several public universities in Croatia. The analysis of responses revealed that students perceive most of the entrepreneurial skills as very important to master. It also revealed that they lack opportunities for service-learning and community engagement during their study. These results will be used to design an academic course that links service-learning and entrepreneurship and enables students to acquire skills that they perceive as relevant for their future careers.
\end{abstract}

Key words: economic and social challenges, civic engagement, service-learning education, skills development, entrepreneurial skills

\section{Introduction}

Faced with the economic, environmental and social challenges, education today is in a very unenviable position. To achieve their full potential as adults, students need to develop a range of skills, such as problem solving, critical thinking, communication, teamwork and self-management. A successful career development depends on the aforementioned set of skills that employees should acquire during their studies through learning that is expanded and enhanced by work-based learning, learning-by-doing or any other innovative teaching and learning practice which builds work-related experience that can help students to become more successful in the modern job market (Pizika, 2014). Universities can provide students with the entrepreneurial learning styles needed to develop higher levels of transferable skills and teach them methods to start and grow their own businesses and thus contribute to the society. One way of incorporating entrepreneurship education into study programs is through academic service-learning, a method that enables the application of what has been learned through an academic course to a project aimed at satisfying a community need (Mikelic Preradovic, 2009). Identifying skills that can and should be acquired through such forms of teaching and students' attitude towards them is of great importance in creation of a curriculum that develops student's entrepreneurship skills through service-learning.

Entrepreneurship as a skill is applicable to all walks of life, which is why it can be categorized as transversal. "It enables citizens to nurture their personal development, to actively contribute to social development, to enter the job market as employee or as self-employed, and to start-up or scale-up ventures which may have a cultural, social or commercial motive." (Bacigalupo et al., 2016: 10).

The entrepreneurial skills cannot be completely separated from the personal characteristics, aspirations and motivations of an individual who possesses them. If students are provided with opportunities for continuous reconfiguration or revision of these skills through innovative forms of entrepreneurial education, apart from their personal development, the foundation for a more stable economy is being created simultaneously. The economic challenges that Europe is currently facing have prompted, among other things, the creation of an Entrepreneurship Competence Framework 
known as EntreComp. EntreComp was developed by the Joint Research Centre (JRC) of the European Commission to improve the entrepreneurial capacity of European citizens as well as their competences. The survey administered in this study (that aimed to research the attitudes of students of information sciences and informatics towards acquiring entrepreneurial skills) was mostly based on the EntreComp framework.

\section{Entrepreneurship education}

Entrepreneurial education is a long-life process, which involves putting ideas into practice, innovation, creativity, risk taking, as well as the ability to plan and manage projects to achieve objectives (Mihalache, 2012). It encompasses opportunity recognition capabilities, as well as skills of commercializing a concept, marshalling resources in the face of risk and initiating a business venture (Jones, English, 2004). It is incumbent upon universities to enable students to develop higher levels of transversal skills. "Essentially, a teaching style that is action-oriented, encourages experiential learning, problem-solving, project-based learning, creativity, and is supportive of peer evaluation. It is thought that such a process best provides the mix of enterprising skills and behaviors akin to those required to create and manage a small business" (Jones, English, 2004: 2).

Lackeus (2015) in his paper on entrepreneurship education assumes the development of a culture that moves "about", "for" and "through" entrepreneurship. Teaching "about" entrepreneurship gives a general theoretical understanding of phenomenon, while teaching "for" entrepreneurship provides a requisite knowledge and skills. Finally, teaching "through" entrepreneurship requires students to experience real entrepreneurial learning (Kyro, 2005, as cited in Lackeus, 2015). According to Bacigalupo (2016: 14), "the progression in entrepreneurial learning is made up of two aspects: a) developing increasing autonomy and responsibility in acting upon ideas and opportunities to create value; b) developing the capacity to generate value from simple and predictable contexts up to complex, constantly changing environments."

The goal is to enable a student to achieve his or her own abilities through the development of the ability to identify, discover and evaluate opportunities, obtain required resources, elaborate business plans, establish a business and provide the management. In non-Economics academic disciplines (such as Information sciences), creating a curriculum with elements of entrepreneurship represents a challenge for teachers due to the lack of required teaching skills in entrepreneurship (Mihalache, 2012). While technical and professional skills are offered as a part of Information Sciences and Informatics curricula in Croatia, entrepreneurial skills are still rarely taught, especially at the introductory-level study, although students need to develop such skills well before they start planning their future careers.

\section{Academic service-learning}

Academic service-learning, an innovative approach to teaching and learning that brings students, academics, and community to jointly develop solutions for challenging issues (Mikelic Preradovic, 2015) is increasingly used in higher education in many parts of Europe (Millican et al., 2019), but so far to a much lesser extent in post-communist countries. For instance, service-learning education is still underrepresented in academic curricula in Croatia (Mikelić Preradović, Mažeikienè, 2019: 180). Higher education, emphasizing cooperation, democratic citizenship and moral responsibility, connects the wider community through service-learning and prepares students to meet the primary needs of society (Astin et al., 2000). Studies show that academic service-learning helps students gain higher levels of problem-solving skills, critical and creative thinking, communication skills, teamwork, interpersonal and intercultural skills, leadership as well as academic skills and personal and civic values (Astin et al., 2000 , Carrington, Selva 2010; Harris, Jones, Coutts 2010; Milne, Gabb, Leihy 2008; Prentice, Robinson 2010; Rochford, 2014).

It is nowadays used in all academic disciplines, not only social sciences and the emphasis is put on the SL in engineering education programs in many EU countries, since it fits well with the descriptors outlined in the requirements of these programs, such as learning from real life situations and heightening social awareness (Mikelić Preradović, Stark, 2019). 
The latest study that measured the impact of SL on students' perceptions of their respective learning processes reports significantly more changes connected to a concept of learning that included contents, behaviors, and personal changes (Macías-Gomez-Estern et al., 2019).

The primary goals of service-learning are structured extensive student reflection, application of learning in real-life settings, and relevant service. It connects students with the community in which they live, encouraging active and purposeful participation in the local community, adopting learning outcomes related to the content of the subject, and finally developing skills and knowledge that help students understand the community needs, which ultimately leads to more active engagement in the community. Students who are working in and for the community enhance their sense of civic responsibility and develop values that underlie action, while improving the quality of life of the entire community.

\section{Methodology}

The general research objective of this study was to determine the need for the education combining academic service-learning and social entrepreneurship in the field of Information Sciences and Informatics.

The specific research objectives were:

- to identify students' attitudes and perceptions towards acquisition of entrepreneurial skills,

- to identify students' attitudes and perceptions towards civic (community) engagement,

- to identify the relevant set of skills required to increase student employability and implement the change in the local community,

- to find out whether a university course that combines academic service-learning and social entrepreneurship is needed to help address entrepreneurial skills shortage.

A survey was created to address the research objectives. A volunteer sample consisting of 211 respondents that chose to respond to the online questionnaire was recruited from the beginning of April to the end of May 2019.

As many as $81.74 \%$ of the volunteer respondents belonged to the age group of $18-21$ years, while the oldest respondent was 26. The volunteer sample included 211 (mostly) undergraduate students of Information Sciences from the Faculties of Humanities and Social Sciences (University of Zagreb, University of Osijek and University of Zadar) as well as students of Informatics from the Faculty of Organization and Informatics (University of Zagreb) and Department of Informatics at the University of Rijeka.

The survey consisted of three parts. The first part examined students' attitudes towards acquiring certain entrepreneurial skills during their studies (through a course on entrepreneurship) and was based on the EntreComp - Entrepreneurship Competence Framework (Bacigalupo et al., 2016), which encompasses 3 competence areas - "Ideas and opportunities", "Resources" and "Into action" - each area including 5 competences which together form "building blocks of entrepreneurship" (Bacigalupo et al., 2016: 1).

The first set of five entrepreneurial skills in EntreComp's framework is represented as "Ideas and opportunities", and covers competences of identifying, harnessing and creating opportunities, as well as consistency in following them: spotting opportunities, creativity, vision, valuing ideas, as well as ethical and sustainable thinking. The ideas include creativity, innovation, risk-taking and the ability to identify positive entrepreneurial patterns as well as usable opportunities.

The other competence area of the framework is named "Resources". These resources represent the entrepreneurial 'know how', financial and economic literacy, self-awareness and self-efficacy, motivation and perseverance, mobilizing resources and others.

The third competence area, "Into action", involves the ability to mobilize and motivate others, taking the initiative, planning and management, coping with the ambiguity, uncertainty and risk, teamwork, collaboration and learning through experience. The order of elements does not imply a sequence in the acquisition process or a hierarchy, i.e. none is more important than the other (Bacigalupo et al., 2016).

After carefully reading each of 44 statements (named "Descriptors" in the EntreComp framework), students expressed a degree of agreement with the statement on a five-point Likert scale ranging from 1 to 5 , in which 1 indicates 'not important' and 5 'very important'. The second part of the survey 
examined students' experiences with community engagement - volunteering and other forms of informal community engagement, aiming to determine the time invested and the most common area of interest. In addition, the general familiarity with the model of service-learning and their views on the strengths and weaknesses of service-learning courses were examined. The last part of the survey collected demographic data.

\section{Results}

The statistical analysis of the results is based on descriptive statistics because the volunteer sample is considered biased (the students who were most likely to participate in the survey voluntarily do not necessarily reflect the whole student population).

The first part of the survey examined respondents' views on entrepreneurial skills through three sets of statements (descriptors), each of which relates to one of three areas within EntreComp's model of entrepreneurial skills. The first group of statements refers to the area "Ideas and possibilities". The largest number of respondents $(69.67 \%)$ considered the descriptor Act responsibly as very important (Figure 1), making it the highest ranked descriptor in this group of statements.

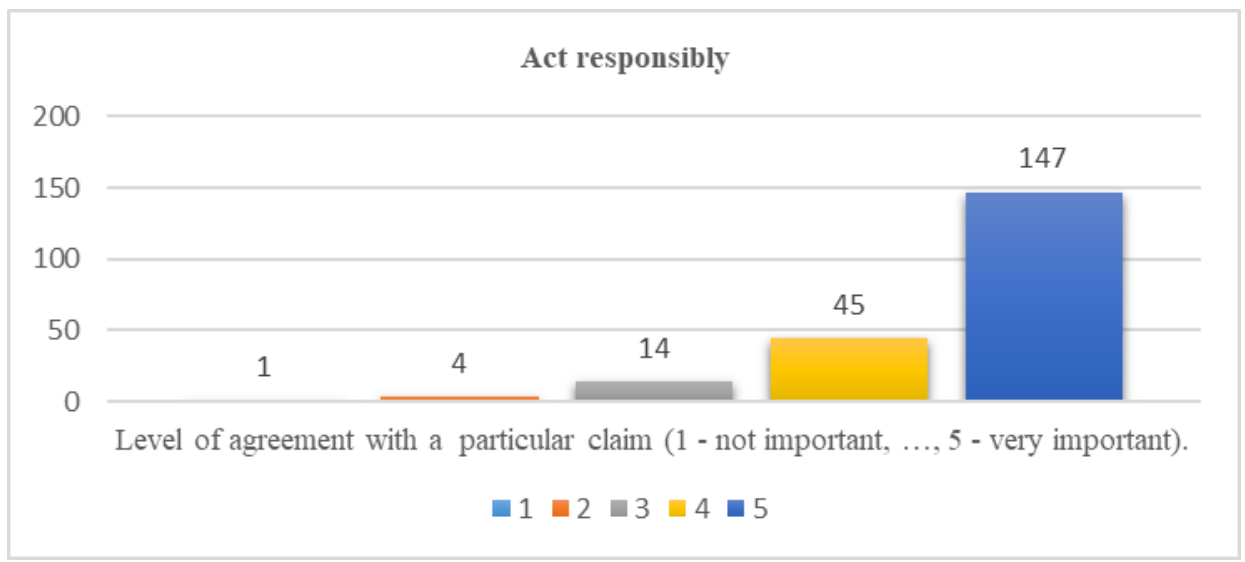

Figure 1. Respondents' opinion on the importance of acting responsibly

The lowest ranked statement in this group was Judge what value is in social, cultural and economic terms. Nobody considered this competence as 'not important', $6.63 \%$ of students opted for 'slightly important', $29.38 \%$ of respondents positioned themselves as 'neutral', while $36.5 \%$ students considered this descriptor as 'important' and $27.5 \%$ of respondents rated the development of this ability in the course on academic service-learning as 'very important' (Figure 2).

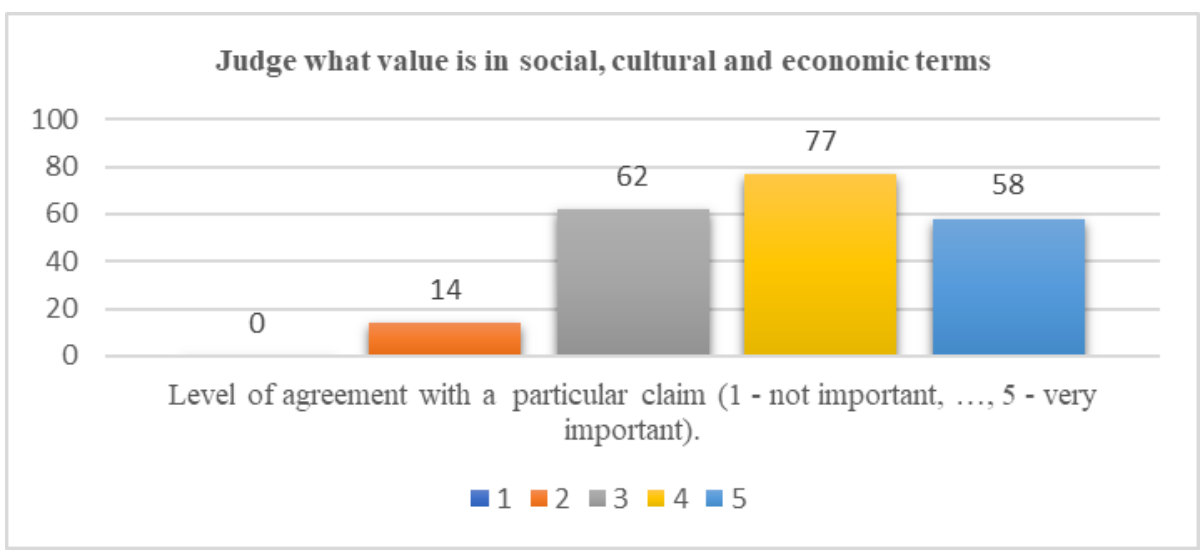

Figure 2. Respondents' opinion on the importance of judging the values in different terms

The second group of statements (descriptors) belongs to the competence area named "Resources", where personal, material and non-material resources are distinguished. The highest ranked statement in this group is Be resilient under pressure, adversity and temporary failure $(68.25 \%$ of participants 
rated this competence as 'very important' for future entrepreneurs), while the descriptor Inspire and enthuse relevant stakeholders has the lowest rank in the group, as presented in Figures 3 and 4.

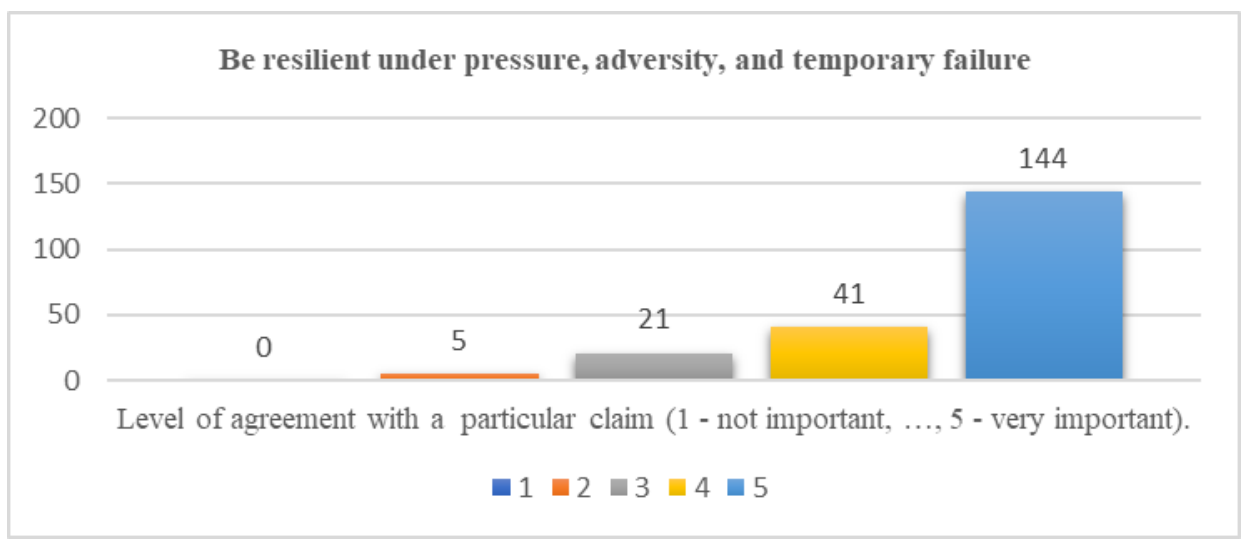

Figure 3. Respondents' opinion on the importance of being resilient

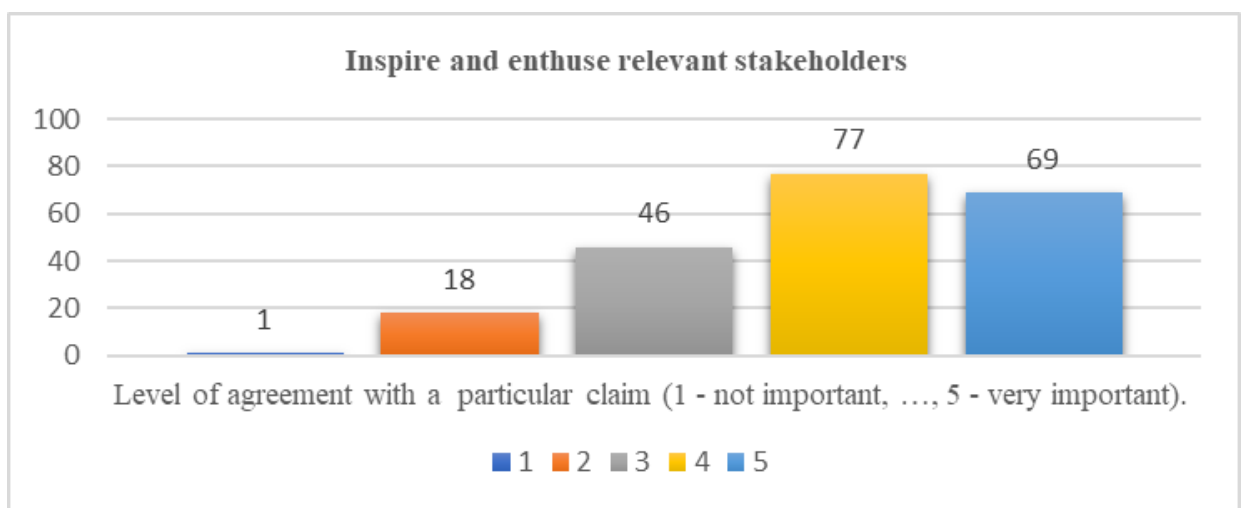

Figure 4. Respondents' opinion on the importance of inspiring and enthusing relevant stakeholders

The last (third) group of statements in this section of the survey relates to the individual's actions. The highest ranked statement in this group is Reflect and learn from both success and failure (your own and other people's), since 121 students $(57.9 \%)$, rated this competence as 'very important' and $31.1 \%$ of students rated it as 'important', as shown in Figure 5.

By defining this competence as the most important in this group of descriptors, students acknowledged that entrepreneurship education through academic service-learning should enable them to experience real entrepreneurial learning, connect theory with practice and reflect upon it through structured reflection.

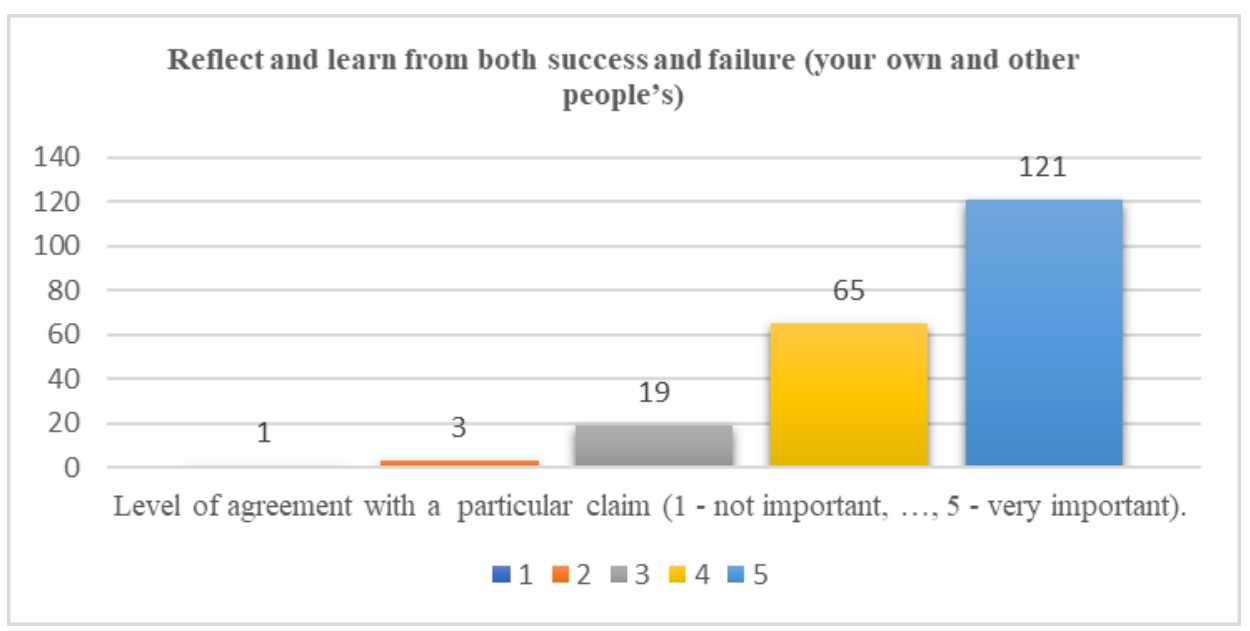

Figure 5. Respondents' opinion on the importance of reflecting and learning from success and failure 
As presented in Fig.6, the descriptor with the lowest rank in the group is related to testing ideas and prototypes from the early stages in order to avoid failure. Just over a quarter, $27.14 \%$ of students positioned themselves as 'neutral', while rating the development of this skill in the course on academic service-learning.

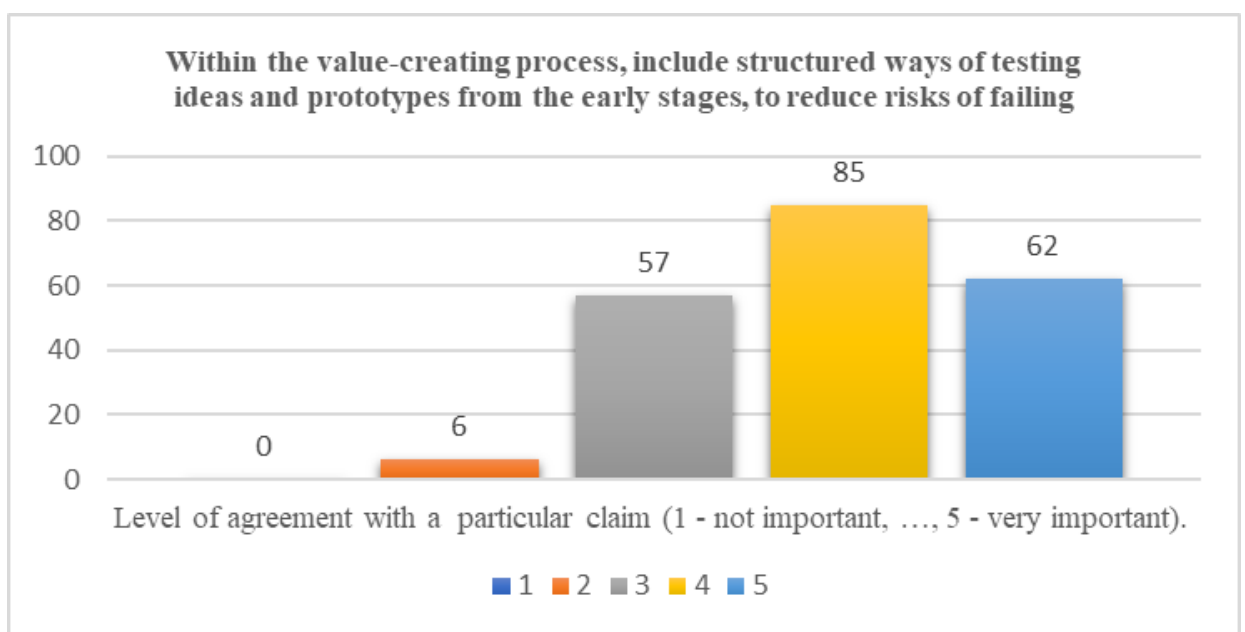

Figure 6. Respondents' opinion on the importance of testing ideas and prototypes to reduce the risk of failure

The results show that the average rating of all three sets of statements in the first part of the survey is approximately equal and very high, 4.2. It is noticeable that students recognize most of the skills and competencies listed in this survey as important or very important for implementation in a course that combines service-learning and entrepreneurship education. These results reveal that students recognize the importance of developing the full range of skills needed to succeed in their careers upon graduation.

The second part of the survey reveals that less than a quarter of respondents, $23 \%$ of them, have volunteered within an organization or informally in their community within the past year from completing the survey. In a comparison with the results reported by the National Council for Voluntary Organizations in England in 2018, according to which as many as 39\% of young people 16 to 24 years have volunteered at least once in the past year and where those who volunteer make up as much as $28 \%$ of the youth population once a month (Department for Digital, Culture, Media and Sport, 2018), this is a small number. However, the number of students in Croatia who made some form of donation during the period of one year before completing our survey is slightly higher. Thus, a total of 80 participants $(38 \%)$ donated money or goods to an organization. Most often donations were made to organizations dedicated to health, animal welfare, youth and national / local development. However, compared to the statistics for England in 2018 (where 57\% of young people aged 16-24 made donations in the four weeks prior to completing their survey), our result indicates that young people in our society are still lagging behind in terms of social awareness, civic and community engagement.

Finally, only $14 \%$ respondents attended a service-learning course, showing that majority of students never had an opportunity to take the course on service-learning. These $14 \%$ of students have recognized the applicability of skills in numerous areas of life and the identification of community needs as the strong points in the course, while at the same time stating that there were no weak points of the course.

\section{Conclusion}

Introducing entrepreneurship education through an academic service-learning course in information sciences and informatics would enables students to acquire skills that they perceive as relevant for their future careers and apply theoretical knowledge or newly acquired skills engaging in meaningful and personally relevant community service while developing capabilities such as problem solving, critical and creative thinking, communication skills, teamwork, interpersonal and intercultural skills, leadership, as well as academic skills and personal and civic values (Astin et al., 2000; Carrington, 
Selva, 2010; Harris, Jones, Coutts, 2010; Milne, Gabb, Leihy, 2008; Prentice, Robinson 2010; Rochford, 2014).

After analysing the results of a survey conducted in five Croatian public universities, we can conclude that students of information sciences and informatics perceive the following entrepreneurial skills as the most important to master: (a) combining knowledge and resources to achieve valuable effects, (b) developing a vision to turn ideas into action, (c) acting responsibly, (d) being resilient under pressure and temporary failure, (e) making the most of limited resources, (f) demonstrating effective communication, persuasion, negotiation and leadership, (g) defining priorities and adapting to unforeseen changes, (h) networking and (i) reflecting and learning from both success and failure.

Likewise, the results revealed that students lack opportunities for service-learning and community engagement during their study, especially at the undergraduate level. Since service-learning education in Croatia is still in the initial phase of institutionalization, it is implemented top-down, starting from the graduate studies, which is a cause for a small percentage of students participating in a servicelearning course.

The results show that there is a need for an undergraduate course that will link service-learning and entrepreneurship and enable students to acquire skills that they perceive as relevant for their future careers, as well as community engagement.

\section{Acknowledgments}

This research is supported by the Erasmus+ Knowledge Alliances Programme of the European Union and is part of the project Rural 3.0: Service Learning for the Rural Development. We wish to thank in particular Philine van Overbeeke from the Rotterdam School of Management of the Erasmus University for the design of the survey.

\section{References}

Astin, A. W., Vogelgesang, L. J., Ikeda, E. K., Yee, J. A. (2000). How service-learning affects students: Executive summary. Los Angeles: Higher Education Research Institute

Bacigalupo, M., Kampylis, P., Punie, Y., Van den Brande, G. (2016). EntreComp: The Entrepreneurship Competence Framework. Luxembourg: Publication Office of the European Union

Carrington, S., Selva, G. (2010). Critical social theory and transformative learning: evidence in pre-service teachers' servicelearning reflection logs. Higher Education Research \& Development 29, 1, 45-57

Department for Digital, Culture, Media and Sport. (2018). Community Life Survey 2017/2018. https://assets.publishing.service.gov.uk/government/uploads/system/uploads/attachment_data/file/734726/Community_L ife_Survey_2017-18_statistical_bulletin.pdf (15.8.2019)

Harris, L., Jones, M., Coutts, S. (2010). Partnerships and learning communities in work- integrated learning: designing a community services student placement program. Higher Education Research \& Development 29, 5, 547-559

Jones, C., English, J. (2004). A contemporary approach to entrepreneurship education. Education \& Training 46, 8-9, 416423

Lackeus, M. (2015). Entrepreneurship in education, what, why, when, how. Entrepreneurship 360 background paper. Paris: OECD

Macías-Gomez-Estern, B., Arias-Sánchez, S., José, M., Macarro, M., Regla Cabillas Romero, M., Martínez Lozano, V. (2019). Does service-learning make a difference? comparing students' valuations in service-learning and non-servicelearning teaching of psychology, Studies in Higher Education. doi: 10.1080/03075079.2019.1675622

Mihalache, M. (2012). Teaching methods for acquiring entrepreneurial skills in higher education in Romania. 2012. https://www.researchgate.net/publication/267626259_teaching_methods_for_acquiring_entrepreneurial_skills_in_higher _education_in_romania (16.8.2019.)

Mikelić Preradović, N., Mažeikienė, N. (2019). Service-learning in post-communist countries. Embedding Service-learning in European Higher Education / Aramburuzabala, P., McIlrath, L., Opazo, H. (eds.), Routledge, London, 180-195

Mikelić Preradović, N., Stark, W. (2019). Identified service-learning practices in European higher education. Embedding Service-learning in European Higher Education. / Aramburuzabala, P., McIlrath, L., Opazo, H. (eds.), Routledge, London, 109-131

Millican, J., Pollack, S., Zani, B., Stark, W., Mikelić Preradović, N., Aramburuzabala, P. (2019) The changing face of higher education. Embedding Service-learning in European Higher Education. / Aramburuzabala, P., McIlrath, L., Opazo, H. (eds.), Routledge, London, 36-50

Mikelić Preradović, N. (2009). Učenjem do društva znanja: teorija i praksa društveno korisnog učenja. Zagreb: Zavod za informacijske studije

Mikelić Preradović, N. (2015). Service-Learning. Encyclopedia of Educational Philosophy and Theory. Peters, M. (ed.), Springer Singapore, 1-6

Milne, L., Gabb, R., Leihy, P. (2008). Good Practice in Service-learning. Melbourne: Post compulsory Education Centre, Victoria University 
Pizika, N. (2014). Embedding Employability Skills in Computer and Information Science Program Curriculum. // World Academy of Science, Engineering and Technology International Journal of Humanities and Social Sciences 8, 2, 381385

Prentice, M., Robinson, G. (2010). Improving Student Learning Outcomes with Service-learning. American Association of Community Colleges

Rochford, R. A. (2014). Service-Learning: A Vehicle for Enhancing Academic Performance and Retention among Community College Developmental Reading and Writing Students. Service-Learning at the American Community College. Community Engagement in Higher Education. / Traver, A. E.; Katz Z. P. (eds). New York: Palgrave Macmillan 